\title{
Impact of Gliricidia Fertilizer Tree Technology on Smallholder Farmers Economic Livelihood in Malawi: Case of Kasungu District
}

\author{
Wisdom Richard Mgomezulu ${ }^{1}$, Abdi-Khalil Edriss ${ }^{1} \&$ Kennedy Machila ${ }^{1}$ \\ ${ }^{1}$ Department of Agricultural and Applied Economics, Lilongwe University of Agriculture and Natural Resources, \\ Bunda Campus, Malawi \\ Correspondence: Wisdom Richard Mgomezulu, Department of Agricultural and Applied Economics, Lilongwe \\ University of Agriculture and Natural Resources, Bunda Campus, Malawi. Tel: 265-8-8452-8590. E-mail: \\ mgomezuluwisdom@yahoo.com
}

Received: September 24, 2018

Accepted: November 11, 2018

Online Published: November 29, 2018

doi:10.5539/jsd.v11n6p162

URL: https://doi.org/10.5539/jsd.v11n6p162

\begin{abstract}
Agriculture plays a huge role in farmer's livelihoods in Africa. With the adverse effect of climate change on agricultural productivity, developing agricultural technologies that are adaptive to climate change is one of the perquisites for agricultural development. Gliricidia intercropping is one of the climate smart agricultural innovations; that is being promoted by most researchers. Gliricidia intercropping has many benefits. Despite evidence of such benefits, there exists some missing literature on the impact of Gliricidia intercropping on farmer's economic livelihoods. The study used cross sectional data collected by ICRAF in Kasungu district which sampled 406 households and employed a Propensity Score Matching method to analyze the effect of Gliricidia intercropping on smallholder farmer's incomes. Results showed that among the observable factors used to match participants and non-participants, hired labour, age, education level, soil type, perception of soil fertility and access to extension services significantly affected participation in Gliricidia intercropping. The Average Treatment Effect on the Treated showed that Gliricidia intercropping improves the economic livelihoods of farmers by increasing household monthly income by MWK 38,565.83 (\$54) at 1 percent significant level. The study went further to conduct sensitivity analysis using the Rosenbaum bounds, and found that unobserved heterogeneity has to increase the odds ratio of participating in Gliricidia intercropping by 10-60 percent before it can negate the estimated ATT. The study then recommends promoting the adoption of Gliricidia intercropping by capitalizing on the factors that influence participation or adoption of Gliricidia intercropping in order to improve smallholder farmers' incomes and hence their livelihoods.
\end{abstract}

Keywords: climate smart agriculture, Gliricidia, livelihoods, PSM, Malawi

\section{Introduction}

The importance of agriculture in farmers' livelihoods in Africa cannot be understated. According to Collier (2007), almost 90 percent of poor people in the continent live in rural areas and most of them depend on farming for their daily food, income and employment. This shows that the agricultural sector is mainly in the hands of small scale farmers who employ traditional methods of production. On the contrary, developing agricultural technologies that are adaptive to climate variability is one of the prerequisites for agricultural development and economic growth in Africa (World Bank, 2014).

According to Shikuku (2015), enhancing farmer's adaptive capacity to climate change and improving food security is at the center stage of many policies in the modern world. World Bank (2014) pointed out the need for intensifying the efforts of promoting climate smart agriculture. Numerous climate smart agricultural technologies have been developed over the past decades. Gliricidia fertilizer tree technology is one of the highly promoted climate smart agricultural innovation that is not only locally appropriate but also helps improve resilience of farming systems to climate variability (Akinnifesi et al., 2010).

Malawi is one of the countries in Sub-Saharan Africa with scarce land, cheap labour, high cost of inputs especially fertilizer but at the same time highly deficient in nitrogen in spite of the fact that the staple crop maize is nitrogen demanding. Many scholars have studied the benefits of fertilizer tree technologies including Gliricidia with the rationale of promoting them (Akinnifesi et al., 2006; Akinnifesi et al., 2010; Mafongonya et al., 2006). Akinnifesi et al. (2010) found that adoption of fertilizer tree systems increase crop yield and improve 
soil health. However, a question still remains of whether these benefits are big enough to affect livelihood outcomes like smallholder farmer's household incomes. Hence the need for a study to link the adoption of fertilizer tree technologies and the impact they have on incomes of smallholder farmers in Malawi. Evaluation of agricultural innovations is really essential as it provides policy makers with information which can help achieve national policies and hence achieve the SDG One of zero poverty by 2030.

\section{Methodology}

\subsection{Empirical Framework}

This section presents the analytical technique used by the study to meet its objective. Impact analysis studied involves comparing two scenarios or groups to ensure that the difference is only attributable to the intervention. The choice of the impact analysis technique however lies on the choice of the counterfactual and the presents of baseline data. The subsections introduces and specifies the Propensity Score Matching technique to impact analysis, the steps followed and the sources of data used.

\subsubsection{The Propensity Score Matching Method}

According to Wooldridge (2015), modelling participation or adoption of a particular technology or innovation can better be presented as a household utility model. With the utility model, the household decides to participate or adopt a technology depending on the utility the household expects to derive from the net returns earned from participating. Therefore, Utility derived by an individual farming household i from adopting Gliricidia intercropping can be presented as follows;

$$
\max \left\{E\left(u\left(\pi_{i}\right)\right\}=f\left(x_{i}\right)+\varepsilon_{i} \quad \mathrm{i}=1, \ldots, \mathrm{n}\right.
$$

Where $U\left(\pi_{i}\right)$ is the expected utility of the ith farmer derived from adopting or not adopting Gliricidia intercropping based on a set of observed covariates given by the function $f\left(x_{i}\right)$ which consist of household specific and institutional specific factors. $\varepsilon_{i}$ is the stochastic error term.

According to Khandker et al. (2010), the first stage of the PSM model involves estimating the probability of participation and getting the predicted estimates as propensity scores. This stage was analyzed by the logit model. Following (Wooldridge, 2015), the logit model can be presented as follows;

$$
\begin{array}{ll}
Y^{*}=\alpha+\beta_{i} X_{i}+\varepsilon_{i} \\
Y_{i}=0 \text { if } & Y_{i}<Y^{*} \\
Y_{i}=1 \text { if } & Y_{i} \geq Y^{*}
\end{array}
$$

Where $\mathrm{Y}_{\mathrm{i}}$ is a binary variable that takes either values of 1 or $0, \mathrm{Y}_{\mathrm{i}}^{*}$ is a latent variable that indexes participation in Gliricidia intercropping, $\mathrm{X}$ is a vector of socioeconomic and institutional variables and $\mathrm{B}$ is a vector of parameters to be estimated. $\varepsilon_{i}$ is the stochastic error term. According to Liebenehm et al. (2011), the predicted or estimated propensity scores from the logit model can be defined as;

$$
P(X)=\operatorname{Pr}(Z=1 \mid x)=F\left(\beta_{i} X_{i}\right)
$$

Thus the scores estimated are strictly between the $[0,1]$ interval (Harder et al., 2010) as the scores follows a probabilistic distribution based on the observable characteristics $\left(\mathrm{X}_{\mathrm{i}}\right)$.

In order to analyze the impact of Gliricidia intercropping on economic livelihood indicator of household expenditure, the Average Treatment effect of the Treated (ATT) was estimated. Following (Caliendo \& Kopeing, 2008), the Average Treatment effect of the Treated can be presented as follows;

$$
\mathrm{ATT}_{\mathrm{PSM}}=\mathrm{E}_{\mathrm{P}(\mathrm{X})}\left\{\mathrm{E}\left(\mathrm{Y}_{1} \mid \mathrm{Z}=1, \mathrm{P}(\mathrm{X})\right)-\mathrm{E}\left(\mathrm{Y}_{0} \mid \mathrm{Z}=0, \mathrm{P}(\mathrm{X})\right)\right\}
$$

Where $\mathrm{E}_{\mathrm{P}(\mathrm{X})}$ is the expected probability with respect to the distribution of the propensity scores estimated, $\mathrm{Y}_{1}$ and $\mathrm{Y}_{0}$ are the outcome variables in the Gliricidia intercropping adopters and non-adopters respectively, $\mathrm{Z}$ is participation taking the values 1 for the adopters and 0 for the non-adopters. The ATT shows the difference between the adopters and non-adopters based on the estimated propensity scores which were estimated on the observable covariates represented by the vector $\mathrm{X}$.

We have hence established that the PSM model constructs a comparison group based on the observable characteristics through a binary choice model and estimates propensity scores: $\mathrm{P}(\mathrm{x})=\operatorname{Pr}(\mathrm{T}=1 \mid \mathrm{x})$. Then under conditional independence and presence of common support assumptions, matching on propensity scores of $\mathrm{x}$ is as good as matching on $\mathrm{x}$ (Khandker et al., 2010). These assumptions can be illustrated as follows;

Under the conditional independence assumption, the selected observable covariates that go into the PSM model 
are independent of the treatment assignment $\mathrm{T}$.

$$
\text { Conditional Independence }\left(Y_{i}^{T} Y_{i}^{C}\right)+T_{i} \mid X_{i}
$$

Under the common support assumption or the overlap condition, treatment observations should have comparison observations based on the observable covariates used to estimate the propensity scores.

$$
\text { Common support } 0<P\left(T_{i}=1 \mid X_{i}\right)<1
$$

Next is to specify the balancing test. According to Khandker et al. (2010), the balancing test is used to specify whether the mean propensity score and the mean of the observable factors are the same within each quantile of the propensity score.

$$
\text { Balancing Test } P(X \mid T=1)=P(X \mid T=0)
$$

Lastly, the estimated ATT has to be checked if it is robust to unobserved heterogeneity. This is achieved by conducting sensitivity analysis. According to Khandker et al. (2010), we have to check whether the treatment effect is affected by unobserved factors. In order to test for this, we assume participation in Gliricidia intercropping is affected by both observed and unobserved factors. We can hence specify the sensitivity analysis as follows;

$$
\text { Sensitivity Analysis } \quad P_{i}=\operatorname{Pr}\left(D_{i}=1 \mid X_{i}\right)=F\left(\beta X_{i}+\Gamma \varepsilon_{i}\right)
$$

Where $\Gamma$ is the effect of the unobserved factors on the participation decision. If the results are free from hidden bias, the value of $\Gamma$ is zero. Khandker et al. (2010) hence suggests a bounding approach to identify the critical level of $\Gamma$ that unobserved factors may assume before negating the estimated ATT.

\subsection{Sources of Data}

The study used data collected by the International Centre for Research in Agroforestry (ICRAF) in 2017. ICRAF implemented a project in Kasungu where farmers adopted fertilizer tree technologies including Gliricidia for four years. This study focused on Gliricidia and evaluated the impact that Gliricidia had on the livelihoods of its adopters in Kasungu district of Malawi. The total sample size was 406 smallholder farmers.

\section{Results and Discussion}

\subsection{Descriptive Statistics}

Descriptive statistics for adopters and non-adopters were computed before the matching was done. The pretreatment variables chosen to match adopters and non-adopters were all chosen from economic theory and previous studied on agroforestry technologies (Akinnifesi et al., 2010). The chi-square test and student t-test for categorical and continuous variables respectively were used to compare the sample Gliricidia adopters and non-adopters. From the observable factors, there were no significant differences in the adopters and non-adopters based on age of the farming household head, land size, gender, access to credit and land tenure. However, there exists some initial bias between adopters and non-adopters based on education, household size, access to extension, perception of soil fertility and soil texture.

Table 1. Socioeconomic and institutional characteristics of respondents

\begin{tabular}{llll}
\hline Variable & $\begin{array}{l}\text { Adopters }(\mathbf{n}=\mathbf{1 7 9}) \\
\text { mean }\end{array}$ & Non-Adopters (n=227) & p-value \\
\hline Continuous & & & 0.0002 \\
\hline Expenditure (MWK) & 153971.4 & 110536.4 & 0.3770 \\
Age & 48.3 & 44.9 & 0.0078 \\
Education years & 6.9 & 5.9 & 0.0211 \\
Household Size & 6.5 & 6.3 & 0.1282 \\
lnlandsize & 111285.2 & 83018.86 & 0.622 \\
\hline Binary & & & 0.736 \\
\hline Gender (male=1) & 0.4464 & 0.5536 & 0.015 \\
Credit access (yes=1) & 0.6592 & 0.6432 & 0.7181 \\
Extension access (yes=1) & 0.8212 & & \\
\end{tabular}




\begin{tabular}{|c|c|c|c|}
\hline \multirow{2}{*}{$\begin{array}{l}\text { Categorical } \\
\text { Perception of Soil Fertility }\end{array}$} & \multicolumn{2}{|l|}{ Percentages } & \multirow[b]{2}{*}{0.016} \\
\hline & & & \\
\hline Poor & 25.14 & 32.89 & \\
\hline Fair & 60.89 & 60.89 & \\
\hline Good & 13.97 & 6.22 & \\
\hline Soil Texture & & & 0.014 \\
\hline Sandy Soil & 56.74 & 60.35 & \\
\hline Red Soil & 30.90 & 19.82 & \\
\hline Dark Soil & 12.36 & 19.82 & \\
\hline Land Tenure & & & 0.921 \\
\hline Purchased & 6.70 & 7.05 & \\
\hline Inherited & 77.65 & 80.62 & \\
\hline Rented Short time & 0.56 & 0.44 & \\
\hline Granted by local leaders & 14.53 & 11.45 & \\
\hline Leasehold & 0.56 & 0.44 & \\
\hline
\end{tabular}

\subsection{Results of the Econometric Model}

The first stage of the PSM model was to estimate the propensity scores using the logit model in order to analyze the observable factors affecting adoption of Gliricidia intercropping. The propensity scores estimated were then used to match adopters and non-adopters. Table 2 shows the results of the participation model.

The overall model was significant at 1 percent $(p=0.0000<0.01)$. The observable covariates were categorized into household specific and institutional factors. Marginal effects were estimated in order to identify the factors that determine participation. As hypothesized; age, education level, perception of soil fertility and hired labour were among the household specific characteristics that positively affected participation in Gliricidia intercropping. Access to extension services was the only institutional factor that significantly and positively affected participation in Gliricidia intercropping. Dark clay soil under soil texture negatively affected participation in Gliricidia intercropping.

The significant positive effect of age may be because older farmers have enough maturity and experience and hence use that in adopting Gliricidia fertilizer tree intercropping technology. Again, the significant positive effect of education may be because educated household heads easily understand the importance and management of agroforestry practices. With regards to hired labour, agroforestry practices tend to be labour intensive hence the positive sign. The negative significant effect of dark clay soil however signifies the fertility of clay soils which reduces the probability of adopting the fertility improving technology. With regards to institutional factors, the positive significant effect of access to extension services might be because extension services involve information essential for adoption and management of agroforestry.

Table 2. Logit model for program selection

\begin{tabular}{llll}
\hline Observable Characteristic & Marginal Effect & Std. Error & P-value \\
\hline Household Specific & & & \\
\hline Gender & 0.0127 & 0.0646 & 0.844 \\
Household Size & 0.0026 & 0.0106 & 0.808 \\
Age & $0.0039^{* *}$ & 0.0017 & 0.027 \\
Education Level (years) & $0.0176^{* *}$ & 0.0078 & 0.024 \\
InLand Size & 0.0294 & 0.0429 & 0.493 \\
\hline Perception of Soil Fertiliry & & & 0.212 \\
$\quad$ Fair & 0.0673 & 0.0539 & 0.012 \\
$\quad$ Good & $0.2288^{* *}$ & 0.0908 & 0.001 \\
\hline Hired Labour & $0.1737^{* * *}$ & 0.0526 & \\
\hline
\end{tabular}




\begin{tabular}{clll}
\hline Soil Type & & & \\
\hline \multicolumn{1}{c}{ Red Soil } & 0.0409 & 0.0602 & 0.493 \\
Dark Clay Soil & $-0.14005^{* *}$ & 0.0644 & 0.030 \\
\hline Institutional factors & & \\
\hline Land Tenure & & \\
\hline Inherited & 0.0673 & 0.0929 & 0.469 \\
Rented short term & -0.0023 & 0.3333 & 0.994 \\
Granted by Local Leader & 0.1681 & 0.1118 & 0.133 \\
Leasehold & 0.104 & 0.3745 & 0.781 \\
\hline Credit Access & 0.0273 & 0.0506 & 0.590 \\
\hline Extension Access & $0.1213^{* *}$ & 0.0566 & 0.032 \\
\hline
\end{tabular}

*** Significant at 1 percent, $* *$ significant at 5 percent

\subsubsection{Choosing a Matching Algorithm}

There are a number of matching algorithms that can be used to match participants and non-participants. These include the kernel matching, caliper matching and the nearest neighborhood matching. All these matching algorithms match participants with non-participants with at least similar propensity scores. The choice of the best matching algorithm however lies on choosing the one with a large matched sample size, low pseudo-R square, large number of insignificant variables after matching and low standardized mean bias (Khandker et al., 2010). The study tested different matching algorithms at different band widths and radiuses. From Table 3 below, kernel matching of band width of 0.1 turned out to be the best matching algorithm as it had a low pseudo-R square, large number of insignificant covariates after matching and the smallest mean bias between the participants and the non-participants after matching. Thus kernel matching of band width 0.1 was selected to match participants and non-participants and then estimate the Average Treatment effect of the Treated.

Table 3. Choice of a matching algorithm

\begin{tabular}{|c|c|c|c|c|}
\hline Algorithm & Number of insignificant variables after matching & Pseudo-R square & Matched sample size & Mean bias \\
\hline \multicolumn{5}{|l|}{ Kernel } \\
\hline Bandwidth 0.1 & 11 & 0.007 & 399 & 4.2 \\
\hline Bandwidth 0.25 & 10 & 0.013 & 399 & 6.2 \\
\hline \multicolumn{5}{|l|}{ Nearest Neighbor } \\
\hline At integer 1 & 10 & 0.019 & 400 & 6.6 \\
\hline At integer 2 & 10 & 0.019 & 400 & 7.1 \\
\hline \multicolumn{5}{|l|}{ Caliper matching } \\
\hline Radius 0.1 & 10 & 0.018 & 399 & 6.3 \\
\hline Radius 0.2 & 10 & 0.019 & 400 & 6.6 \\
\hline
\end{tabular}

\subsubsection{Matching Quality}

Following Caliendo and Kopeinig (2008), checking for the matching quality is another important step in analyzing the validity of the propensity scores. This step involves checking the common support region so that only participants and non-participants of similar characteristics are compared to each other when estimating the ATT. Figure 1 shows the distribution of the propensity scores. The common support assumption is satisfied as adopters and non-adopters have been matched based on the observable characteristics. 


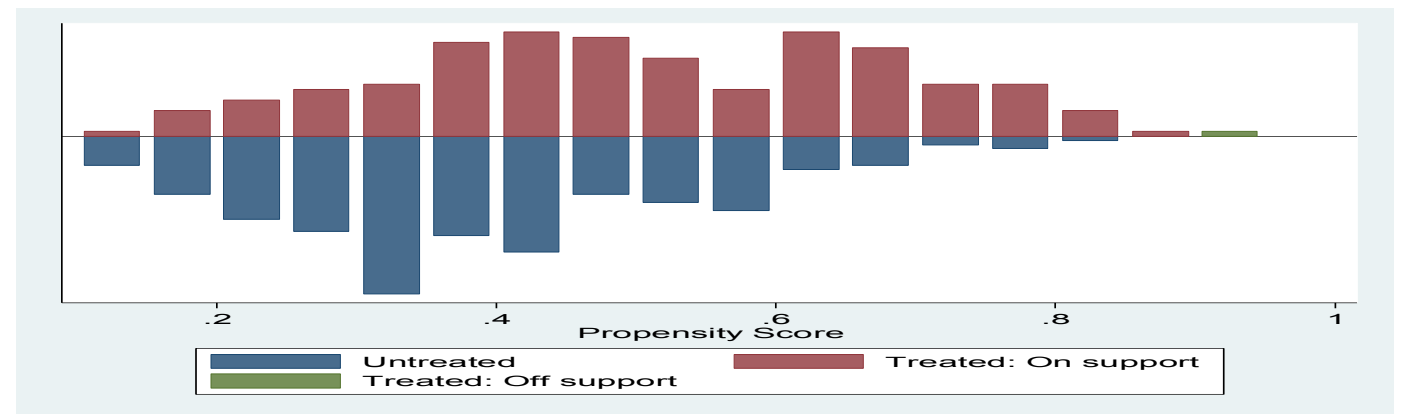

Figure 1. Matching quality

\subsubsection{Average Treatment Effect of the Treated (ATT)}

This stage involves the estimation of the impact of adopting Gliricidia intercropping using the selected outcome variables. Thus after estimating the ATT, we can safely conclude that any significant difference between the adopters and the non-adopters can only be attributed to adopting Gliricidia intercropping alone. The significant differences were analyzed based on one outcome variable, which is the total of household expenditure that was a proxy for household income.

From Table 4, before matching was done, the average expenditure of Gliricidia intercropping adopters was MWK 154,171.89 (US\$1=MWK730) and that of non-adopters was MWK 110,731.17 meaning that before matching, on average adopters had their expenditures MWK 43, 440.71 more than those of non-adopters. After matching and controlling for all factors, the difference between the average expenditures between Gliricidia intercropping adopters and non-adopters reduced to MWK 38, 565.83 but it was still significant at 1 percent level of significance. This implies that adoption of Gliricidia intercropping has a positive and significant effect on expenditure or incomes of farming households and thus improving their economic livelihoods. The difference in expenditures or incomes between the adopters and non-adopters can in this case be attributed to Gliricidia intercropping and Gliricidia intercropping alone.

Table 4. Impact of Gliricidia intercropping

\begin{tabular}{lllllll}
\hline Outcome & Sample & Treated & Controls & Difference & Std. Error & t-value \\
\hline Expenditure & Unmatched & 154171.89 & 110731.17 & 43440.71 & 11858.94 & $3.66^{* * *}$ \\
& ATT & 153929.06 & 115363.23 & 38565.83 & 13455.83 & $2.87 * * *$ \\
\hline
\end{tabular}

$* * *, * *$ and $*$ represent significance at $1 \%, 5 \%$ and $10 \%$ respectively.

\subsubsection{Robustness of the Results}

According to Khandker et al. (2010), the last step of PSM technique is to check for the robustness of the results. Results in impact analysis can be affected by unobserved heterogeneity. Thus we estimate values of Gamma that the observed variables would have to increase the odds ratio of participating in Gliricidia intercropping before it can affect the estimated ATT (Jema and Belaineh, 2017). From Table 5, the results show that the matching was of good quality. According to Caliendo and Kopeinig (2008), the acceptable range of the mean of the standardized bias (SB) should be 3-5 percent after matching. The mean SB of 4.2 percent is thus within acceptable range. With regards to cases lost to the common support (CS), only 1 case was lost which was reported as off-support. This gives a 0.25 percent loss which according to Khandker et al. (2010) is within acceptable range. Thus a good standardized bias, fairly low percentage of cases lost to common support and a very low pseudo-R square indicates the quality of the matching indicators.

With regards to sensitivity analysis, the assumption of un-confoundedness ensures that the estimated effect is not susceptible to unobserved heterogeneity. The Rosenbaum bounds (rbounds) were installed in Stata and sensitivity analysis to unobserved heterogeneity was estimated. For the outcome variable of expenditure, the critical values of gamma $(\Gamma)$ ranged from 1.1 to 1.6 . This implies that the unobserved variable should have to increase the odds ratio of participation in Gliricidia intercropping by 10 to 60 percent before it would affect the estimated effect of participation (Loos and Zeller, 2014). Since the critical values of gamma are within 
acceptable range, the study safely concludes that the estimated ATT is robust to confounding factors (Rosenbaum, 2002).

Table 5. Robustness of results

\begin{tabular}{lllll}
\hline Participation Variable & $\mathbf{S B}_{\text {After Matching }}$ & Cases lost to CS & Pseudo- $^{\mathbf{2}}$ & Critical values of gamma ( $\boldsymbol{\Gamma})$ \\
\hline Gliricidia Intercropping & 4.2 & 1 & 0.007 & $1.1-1.6$ \\
\hline
\end{tabular}

\section{Conclusions and Recommendations}

Fertilizer tree technologies are essential in improving soil fertility and crop yields of smallholder farmers. Gliricidia is one of the fertilizer tree technologies that most farmers intercrop with their maize to improve their crop yields. This study therefore analyzed the effect of Gliricidia intercropping on smallholder farmer's household incomes (proxy expenditures). In order to establish causality between Gliricidia intercropping and the expenditures of smallholder farmers, the study employed the PSM model that matched participants and non-participants based on observable household specific and institutional factors. The study found a significant effect of Gliricidia intercropping on the economic livelihood indicator of expenditure. Expenditure was aggregated and used as a proxy for household income. The ATT for expenditure was significant at 1 percent level of statistical significance showing that the difference between the expenditures of the adopters and non-adopters was due to Gliricidia intercropping. The study hence recommends intensifying extension services and training smallholder farmers on agroforestry practices in order to increase adoption rates of Gliricidia fertilizer trees and hence improve smallholder farmers' incomes.

\section{Acknowledgements}

The authors would like to acknowledge the efforts of all people who directly or indirectly assisted in writing this paper. Special thanks should go to the Department of Agricultural and Applied Economics for allowing the authors to have the much needed time in writing this paper. We would like to also commend African Economic Research Consortium (AERC) for its financial support in conducting the research.

\section{References}

Akinnifesi, F. K., Chirwa, P. W., Sileshi, G., Kwesiga, F. R., Harawa, H., \& Makumba, W. (2010). Contributions of agroforestry reserach to livelihoods of farmers in Sub-Saharan Africa. Agricultural Journal of Economics, 4 (2), 61-72. $\quad$ Retrieved from https://www.researchgate.net/publication/285705366_Contributions_of_agroforestry_research_to_livelihoo d_of_smallholder_farmers_in_Southern_Africa_1_Taking_stock_of_the_adaptation_adoption_and_impact _of_fertilizer_tree_options

Akinnifesi, F. K., Makumba, W., \& Kwesiga, F. (2006). Sustainably producing maize using gliricidia/maize intercropping in Southern Malawi. Agricultural Journal of Economics 7(3), 448-454. Retrieved from https://www.doc-developpement-durable.org/file/Fertilisation-des-Terres-et-des-Sols/fertilisation-par-glirici dia/SUSTAINABLE\%20MAIZE\%20PRODUCTION\%20USING\%20GLIRICIDIA-MAIZE\%20INTERC ROPPING.pdf

Caliendo, M., \& Kopeing, S. (2008). Some Practical Guidance for the Implementation of Propensity Score Matching. Journal of Economic Survey, 31-72. Retrieved from http://ftp.iza.org/dp1588.pdf

Collier, P. (2007). The bottom billion: why the poorest countries are failing and what can be done to resolve this. Oxford: Oxford University Press.

Harder, U. S., Stuart, E. A., \& Anthony, J. (2010). Propensity Score Technique and Assessment of Measured Covariate Balance to Test Causal Associations in Psychological Research. Psychological Methods, 234-249. https://doi.org/10.1037/a0019623

Jema, H., \& Belaineh, L. (2017). Impact of sedentarization program on the livelihood and food security of Ethiopian pastoralists. Journal of Arid Environmentaralist, 136(1), 45-53. Retrieved from http://www.researchgate.net/publication/309546005

Khandker, S. R., Koolwal, G. B., \& Samad, H. A. (2010). Handbook on Impact Evaluation: Quantitative Methods and Practices. Washington D.C: The World Bank. 
Loos, T. K., \& Zeller, M. (2014). Milk sales and dietary diversity among the Masai. Journal of International Association of Agricultural Economists, 12(1), 70-90. https://doi.org/10.1111/agec.12131

Mafongonya, P. L., Bationo, A., Kihara, J., \& Waswa, B. S. (2006). Appropriate technologies to replenish soil fertility in Southern Africa. Agroecosys, 76(2), 137-151. Retrieved from https://link.springer.com/article/10.1007/s10705-006-9049-3

Rosenbaum, P. R. (2002). Observational studies. New York: Springer. https://doi.org/10.1007/978-1-4757-3692-2

Shikuku, P. (2015). A cost function analysis of trade-offs in climate smart agriculture: does mulching save the cost of crop production among smallholder farmers in Uganda? Journal of Agricultural Economics, 14(2), 35.

Retrieved

from https://ageconsearch.umn.edu/record/212238/files/Shikuku-A\%20cost $\% 20$ function $\% 20$ analysis\%20of\%20t rade-offs\%20within\%20climate-smart\%20agriculture-42.pdf

Wooldridge, J. M. (2015). Introductory Econometrics: A Modern Approach. Michigan: Michigan State University.

World Bank. (2014). Addressing the food crisis: governance, market functions, and investments in public sector. Washington D.C: World Bank.

\section{Copyrights}

Copyright for this article is retained by the author(s), with first publication rights granted to the journal.

This is an open-access article distributed under the terms and conditions of the Creative Commons Attribution license (http://creativecommons.org/licenses/by/4.0/). 